\title{
Earthquake Prediction in Physical Effects
}

\author{
Yaozhi Jiang ${ }^{1}$ \\ ${ }^{1}$ Shijiazhuang High-Tech District, Hebei, China \\ Correspondence: Yaozhi Jiang, Shijiazhuang High-Tech District, Hebei, China. E-mail: jiangyaozhi@ 126.com
}

Received: February 2, 2019

Accepted: March 7, 2019

Online Published: June 25, 2019

doi:10.5539/esr.v8n2p17

URL: https://doi.org/10.5539/esr.v8n2p17

\begin{abstract}
In the paper author describes an opinion which is based on: the crustal plate latitude direction force created by the variety of earth rotation angular velocity and the crustal plate longitude direction force created by earth rotation are main forces which are able to cause earthquake. At same time, author gives estimated value of these forces on main crustal plates around earth, and describes that five physical effects which can be used in earthquake prediction.
\end{abstract}

Keywords: latitude direction force, longitude direction force, ideal micro-elastic solid, isotropic solid, stress-strain state

\section{Introduction}

Earthquake as a natural calamity usually occurs on earth, but the knowledge involved earthquake we have known a little up to now, even the force produces a earthquake can not be correctly analyzed. Author try to solve the problem and give an answer.

\section{Some Definitions and Data Used in Some Conceptions, Hypothesis and Constant Values Involved Earth Used in the Paper are Defined as Below}

a. Earth is an ideal micro-elastic spherical body, its solid mechanics property is satisfied by Hooke's law within yield strength;

b. Radius of the earth is $6380(\mathrm{Km})$;

c. Rotation angular velocity of earth is variety within annual period, its maximum instantaneous angular acceleration

$$
\alpha= \pm 1.03 \times 10^{-10}\left(1 / \mathrm{sec}^{2}\right) ;
$$

d. Crustal plates around earth consist of granite and basalt (between them is the Conrad) which are isotropic shell;

e. The average thickness $h$ of crustal plates around earth are $h=33(\mathrm{Km})$, its maximum thickness is $h_{\max }=70(\mathrm{Km})$, its minimum thickness is $h_{\min }=4(\mathrm{Km})$;

f. Under granite and basalt is the Moho and under the Moho is the Gutenberg, between the Moho and Gutenberg is mantle, which is a matter with creep property, under the Gutenberg is core of the earth;

g. Average density $\rho$ of crustal plate around the earth

$$
\rho=2.8 \times 10^{9}\left(\mathrm{KKg} / \mathrm{Km}^{2}\right)
$$

h. Crustal plates surrounded by fracture zones to divide to several plates and to extrude each other;

i. Crustal plate fracture zones stretched by pull force would make the fracture zone become wider and wider, then make the mantle matter flow up to become a condensed zone, the zone can be called up-to-condense fracture zone;

j. Crustal plates fracture zones compressed by compression force would make the one or two crustal plates dawn into mantle matter under both sides of the fracture zone, then make the crustal plates melted to become to mantle matter, the zone can be called down-to-melt fracture zone;

k. Earthquake is caused by releasing suddenly elastic energy stored from the stress-strain state formed by 
breaking, sliding produced by stretch, compression among the crustal plates each other.

\section{The Force Analysis on Crustal Plate}

The three main forces are analyzed as below.

3.1 Crustal Plate Latitude Direction Force P Caused by Earth Rotation Maximum Instantaneous Angular Acceleration

$$
P=\operatorname{mr} \alpha(\cos A)
$$

In the formulation above,

$$
m \text { - mass of the crustal plate, }\left(\mathrm{KKg} / \mathrm{Km}^{3}\right)
$$

$A$ - latitude angle of the crustal plate mass center;

$\alpha$ - maximum instantaneous angular acceleration of the earth rotation;

The direction of force $P$ is parallel to latitude and vertical to longitude, i.e. vertical to the page surface, which crossed on mass center.

3.2 Crustal Plate Longitude Direction Force F

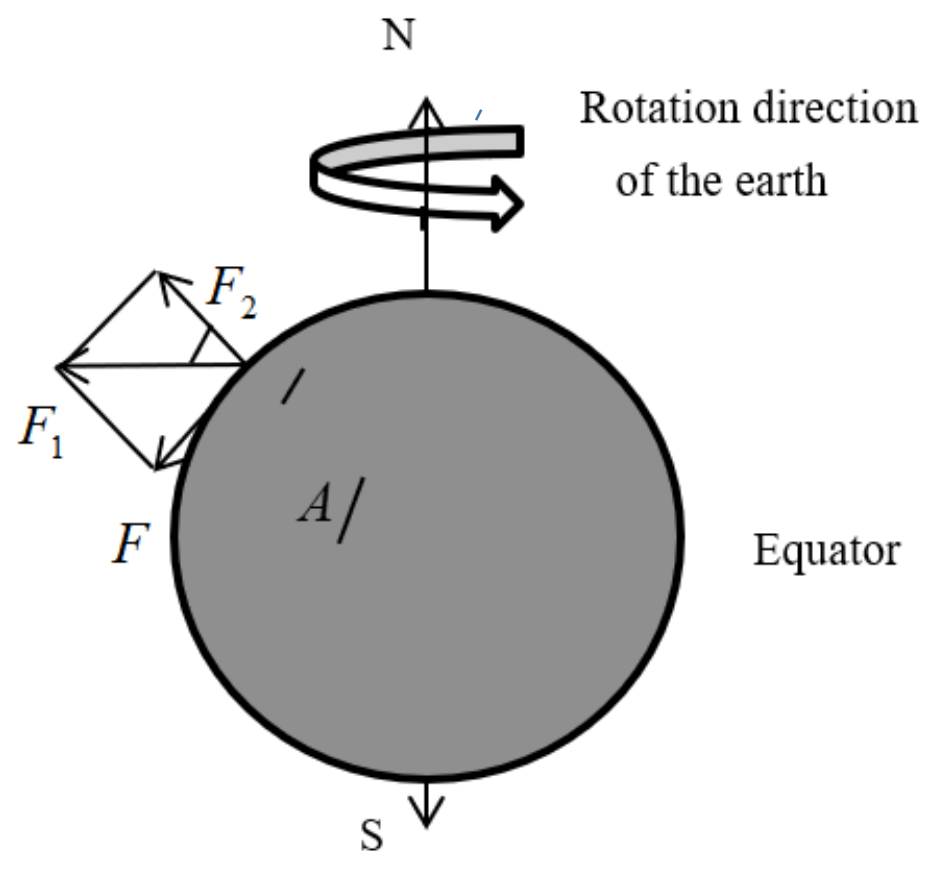

Figure 1. Crustal plate longitude direction force $F$

As shown as Fig. 1, when earth is rotating, the mass center of crustal plate must produce a force $F_{1}$ which is rotation centrifugal force and can be decomposed to two force : the first force is self-attractive force $F_{S}$ follow to earth center direction, which is balanced to earth center direction centrifugal force $F_{2}$, and the second force is the longitude direction force $F$, the force is vertical to the latitude, and

$$
F=F_{1}(\sin A)=m \omega^{2} r(\sin A)(\cos A)=\frac{1}{2} m \omega^{2}(\sin 2 A)
$$

in the formulation as above,

$$
\omega \text {-self-rotation angular velocity of the earth, } \omega=7.268518519 \times 10^{-5}(1 / \mathrm{sec}) \text {; }
$$


$A$ - the latitude angle of mass center.

3.3 Centrifugal force $F_{2}$ of Earth Crustal Plate

$$
F_{2}=m g
$$

In the formulation as above,

$$
g \text {-acceleration of earth gravity, } g=9.8 \times 10^{3}\left(\mathrm{Km} / \mathrm{sec}^{2}\right)
$$

\section{Stress Analysis Based on the Section 3}

Only three main stresses are explained as below.

4.1 Stress $\sigma_{1}$ caused by crustal plate latitude direction force $P$

$$
\sigma_{1}=P / h L_{P}
$$

In the formulation above, $L_{P}$-crustal plate projected length on longitude, $(\mathrm{Km})$;

4.2 Stress $\sigma_{2}$ caused by crustal plate longitude direction force $F$

$$
\sigma_{2}=F / h L_{F}
$$

In the formulation as above, $L_{F}$ - the crustal plate projected length on latitude, $(\mathrm{Km})$;

4.3 Stress $\sigma_{3}$ caused by centrifugal force of the earth crustal plate $F_{2}$

$$
\sigma_{3}=\rho g h
$$

In the 4.1, 4.2., and 4.3 above, stress unit all are $\mathrm{MPa}$.

Table 1. Inner dynamics parameters table of main eight crustal plate

\begin{tabular}{llllll}
\hline & $\begin{array}{c}\text { Mass } m \\
\text { Name }\end{array}$ & $\begin{array}{l}\text { latitude } \\
\text { angle } A\end{array}$ & $\begin{array}{l}\text { Rotation inertia force } P \\
\times 10^{19} \mathrm{Mg}\end{array}$ & & longitude direction force \\
& & & & $F \times 10^{12} \mathrm{MN}$ & \\
\hline Pacific plate & 1.25 & 0 & 8.21 & 0 \\
Eurasian plate & 0.96 & $45^{0} \mathrm{~N}$ & 3.7 & 1.5297 \\
Indian plate & 0.51 & $10^{0} \mathrm{~S}$ & 3.3 & 0.2940 \\
African plate & 0.74 & $10^{0} \mathrm{~S}$ & 4.78 & 0.4265 \\
Australian plate & 0.37 & $33^{0} \mathrm{~S}$ & 2.04 & 0.5697 \\
North American & 0.51 & $45^{0} \mathrm{~N}$ & 2.36 & 0.8595 \\
plate & & & & 1.1822 \\
$\quad$ South & 0.81 & $30^{0} \mathrm{~S}$ & 4.61 & 0 \\
American plate & & & & \\
Antarctic plate & 0.44 & $90^{\circ} \mathrm{S}$ & 0 & & \\
\hline
\end{tabular}




\section{Characteristic on Crustal Plate Surround Earth}

The fracture zones of crustal plate surround earth can be divided into four types: fracture zone of compression stress, fracture zone of stretching stress, fracture zone of bending stress, and fracture zone of sliding friction.

The Atlantic N-S fracture zone and the east Pacific N-S fracture zone are all the well-known fracture zone stretched by pull force, therefor they are all the well-known up-to-condense zone.

The Mediterranean Crete trench fracture zone, the Himalayas fracture zone and the Indonesia fracture zone are all compression stress fracture zone; the Kamchatka fracture zone, Mariana trench fracture zone and eastern Indonesian trench are all fracture zone of bending stress. These fracture zones are all down-to-melt fracture zone.

The fracture zones surround the Caribbean Islands exist a fracture zone of bending stress, therefor it is a down-to-melt fraction zone.

\subsection{The Two Force-Triangle May Be Noticed}

The two force-triangle may be noticed, one of them is Indonesia-triangle, another of them is Caribbean-triangle. These two triangle are covered almost strong earthquake zone.

\subsubsection{Indonesia-Triangle}

The first edge of Indonesia-triangle is the Atlantic N-S fracture zone; the second edge is connected from northern point, nearby the Iceland, of the Atlantic N-S fracture zone to the Indonesia; the third edge is connected from southern point, nearby the point of $50^{\circ} \mathrm{S}, 10^{\circ} \mathrm{W}$, of the Atlantic N-S fracture zone to the Indonesia.

The point on the equator of Indonesia-triangle is Indonesia, the Indonesia is a famous strong earthquake zone.

\subsubsection{Caribbean-Triangle}

The first edge is the east Pacific N-S fracture zone; the second edge is connected from northern point, nearby the Gulf of Alaska, of the Pacific N-S fracture zone to the Caribbean Islands; the third edge is connected from southern point, nearby the point of $50^{\circ} \mathrm{S}, 112^{\circ} \mathrm{E}$, of the Pacific N-S fracture zone to the Caribbean Islands.

The point on the equator of Caribbean-triangle is Caribbean Islands, the Caribbean Islands is a famous strong earthquake zone.

\subsection{Macro-Law of Earthquake Fracture Zone Within China}

There are three steps of China's terrain: eastern plain, central mountains and western plateau. In the eastern plain there are N-S and W-E earthquake fracture zones, in the central mountain there are included angle $61^{\circ}$ between the equator and fracture zones, this shows that central mountain fracture zones are sliding friction zones, the " included angle $\frac{\pi}{4} \times 57.32^{\circ}$ between the equator and fracture zones" is satisfied the basic law in solid mechanics that is " brittle material forced by compression stress would be broken to slide away follow the direction of included angle $\frac{\pi}{4} \times 57.32^{\circ}$ between force direction and sliding surface." And shows that "if vector $R$ is the sum vector of crustal plate latitude direction force $P$ and crustal plate longitude direction force $F$, then included angle between the vector $R$ and vector $F$ is equal to $61^{0}-\frac{\pi}{4} \times 57.32^{0}=16^{0}$.

\subsection{Average Positive Stress Value of Fracture Zone Within China}

Using octahedron normal stress strength criterion formula, in which the stretch stress is positive and the compression stress is negative, i.e.

$$
\tau_{8}=\frac{1}{3}\left[\left(\sigma_{1}-\sigma_{2}\right)^{2}+\left(\sigma_{2}-\sigma_{3}\right)^{2}+\left(\sigma_{3}-\sigma_{1}\right)^{2}\right]^{\frac{1}{2}}
$$


we can obtain the maximum shearing stress value within China is $\tau_{8}=106(\mathrm{MPa})$, in which the thickness of crustal plate is $33(\mathrm{Km})$ and if given the thickness of crustal plate is $10(\mathrm{Km})$ then the $\tau_{8}=350(\mathrm{MPa})$, this value is going beyond the limit strength value of granite and basalt, the limit strength value of granite is $\tau_{G} \leq 70(\mathrm{MPa})$ and the limit strength value of basalt is $\tau_{B} \leq 80(\mathrm{MPa})$, thus that strong earthquake produced constantly within China is a something understandable .

6. The Five Physical Macro-Effects in Stress-Strain State of Crustal Fracture (Uyedas \& Kamogawa, 2009; Guo, Yang \& Liu, 1990)

The granite and basalt are all material constructed of crystal lattice, under the condition of stress-strain state would produce a series of physical effects, such as electrostatic yield effect, air ionized effect, electromagnetic wave effect, radiation effect, sound wave effect, etc., which are basic information can be used in the earthquake prediction. These effects sensed by animals would change animals' behavior. (Kirschvink, 2000; Quammen, 1985; Schaal, 1988).

\subsection{Positive Electron Effect}

The granite and basalt are all material constructed of crystal lattice. Among the crystal lattices, common electron or common ion is using to link every adjacent crystal lattice. Under the stress-strain state condition the breaking crystal in crustal fracture will make common condition of the common electron or common ion to change, so that the breaking place would produce "electron shortage" and therefor would produce "positive electron effect". The effect would produce a large scale field effect and current.

\subsection{Air Ionized Effect}

Because of the resistance of granite and basalt is bigger, so that the breaking place would produce high-voltage electrostatic field. The yield would make air nearby earth surface to positive ionize, in additional, the electronic radiation also would produce the light radiation, therefor there appear orange purple "earth light", the nitrogen in air ionized will produce the orange purple light, or earthquake-type lightning, and would attract the negative ionized vapour clouds to the broken place, then, to the earthquake-type rain.

\subsection{Electromagnetic Wave Effect}

Under the condition of stress-strain state, the breaking place of crystal lattice of granite and basalt would radiate electromagnetic wave, and would change earth magnetism value of the breaking place.

\subsection{Sound Wave Effect}

Under the condition of stress-strain-state, the breaking place of crystal lattice of granite and basalt would produce mechanic wave, which can be divided into sound wave, supersonic wave, infrasonic wave.

\subsection{Radiation Effect}

Normally, there exists some radiation elements, such as uranium, cerium, etc., in the granite and basalt. Under the condition of stress-strain state, the radiation strength of the radiation elements would be changed.

\section{Conclusion}

As shown above, author has explained the basic characteristic property of crustal fracture of the earth, and analyzed three main inner forces caused by the rotation of earth. At same time, author has estimated the three main inner forces acted on the eight main crustal plate around the earth, and shearing stress value of crustal fracture zone on the central mountain within China. At the end, author has shown the physical effect caused by earthquake to predict earthquake.

\section{References}

Guo, Z. Q., Yang, H. T., \& Liu, B. (1990). Quantum chemical model for fracture initiation of granite. Journal of Geophysics, 4.

Kirschvink, J. L. (2000). Earthquake Prediction by Animals: Evolution and Sensory Perception, Bull. Seism. Soc. Am., 90, 312-323.

Quammen, D. (1985). Animals and earthquakes: This world, San Francisco chronicle, April 21, 15-16.

Schaal, R. B. (1988). An Evaluation of the Animal Behavior Theory for Earthquake Prediction, California Geology, 41(2).

Uyedas, N. T., \& Kamogawa, M. (2009). Short-term earthquake prediction: Current Status of Seismo-Electromagnetics. Tectono-physics, 470(3-4), 205-213. 


\section{Copyrights}

Copyright for this article is retained by the author(s), with first publication rights granted to the journal.

This is an open-access article distributed under the terms and conditions of the Creative Commons Attribution license (http://creativecommons.org/licenses/by/4.0/). 